Anales de Geografía de la Universidad Complutense ISSN: 0211-9803

http://dx.doi.org/10.5209/AGUC.64683

\title{
Los desajustes entre la organización político-administrativa y las realidades territoriales: La articulación funcional del Valle del Tiétar Abulense
}

\author{
Miguel Ángel Troitiño Vinuesa ${ }^{1}$; Libertad Troitiño Torralba ${ }^{2}$ \\ Recibido: 15 de marzo del 2018/ Enviado a evaluar: 20 de mayo del 2018/ Aceptado: 27 de febrero del 2019
}

Resumen. El municipio, entidad administrativa histórica, tiene múltiples dificultades para ser una unidad eficiente en el gobierno actual del territorio español, sin embargo, por la "sacralización" del mapa municipal y provincial, está resultando muy difícil perfilar entidades de escala intermedia, comarcas o áreas funcionales, que respondan a los problemas y las demandas sociales existentes, resultando evidente, en el caso de Castilla y León, la necesidad de revisar en profundidad el modelo de organización y gestión del territorio rural. En este artículo, centrado en el valle del Tiétar Abulense, tras presentar la organización político administrativa de la comarca, se analizan las características del poblamiento, el crecimiento explosivo del parque edificado por el protagonismo desmedido de la residencia secundaria y los cambios tipológicos y morfológicos de los asentamientos (núcleos tradicionales, ensanches, urbanizaciones y diseminados), para concluir explicando la articulación funcional e identificando los núcleos rectores del territorio.

Palabras clave: Territorio; Valle del Tiétar; Gobierno; Estrategia de desarrollo sostenible.

[en] The imbalances between the political-administrative organization and the territorial realities: The functional articulation of the Tiétar Abulense Valley

\begin{abstract}
The municipality is a historical administrative entity, which has many difficulties to be an efficient unit in the current government of the Spanish territory, however, by the "enshrinement" of the municipal and provincial map, it is proving very difficult to outline entities of intermediate scale, counties or areas Functional, that respond to the problems and the existing social demands, being evident, in the case of Castilla y Leon, the necessity to review in depth the model of organization and management of the rural territory. This report is focused in the valley of Tiétar (Ávila province), after to introduce the administrative political organization of the region, the characteristics of the settlement are analysed, the explosive growth of the park built by the excessive prominence of the secondary residence
\end{abstract}

$1 \quad$ Universidad Complutense de Madrid.

E-mail: matroiti@ghis.ucm.es

2 Universidad Complutense de Madrid.

E-mail: 1troitin@ghis.ucm.es 
and the typological and morphological changes of the settlements (traditional centres, expansions, urbanizations and disseminations), to conclude explaining the functional articulation and identifying the governing centres of the territory.

Key Words: Territory; Valley of Tiétar; Government; Strategy of Sustainable Development.

[fr] Les déséquilibres entre l'organisation politico-administrative et les réalités territoriales: l'articulation fonctionnelle de la vallée de Tiétar Abulense

Résumé. La municipalité, entité administrative historique, éprouve de nombreuses difficultés à être une unité efficace dans le gouvernement actuel du territoire espagnol. Toutefois, en raison de la "sacralisation" de la carte municipale et provinciale, il est très difficile de définir des entités, des régions ou des zones de taille intermédiaire. fonctionnelles, qui répondent aux problèmes existants et aux demandes sociales, étant évident, dans le cas de Castilla y León, la nécessité de revoir en profondeur le modèle d'organisation et de gestion du territoire rural. Dans cet article, centré sur la vallée de Tiétar Abulense, après avoir présenté l'organisation politique et administrative de la région, les caractéristiques de la colonie sont analysées, la croissance explosive du parc construit par la proéminence excessive de la résidence secondaire et les changements typologiques et morphologiques de les implantations (noyaux traditionnels, extensions, urbanisations et disséminés), pour conclure en expliquant l'articulation fonctionnelle et en identifiant les noyaux directeurs du territoire.

Mots Clés: Territoire; La vallée de Tiétar; Le gouvernement; Stratégie de développement durable.

Cómo citar. Troitiño Vinuesa, M.A. y Troitiño Torralba, L. (2019): Los desajustes entre la organización político-administrativa y las realidades territoriales: La articulación funcional del Valle del Tiétar Abulense. Anales de Geografía de la Universidad Complutense, 39(1), 201-222.

Sumario. 1. Organización político administrativa y gobierno del territorio. 2. Organización políticoadministrativa del Valle del Tiétar. 3. Estructura y características básicas del doblamiento. 4. Crecimiento explosivo del parque edificado y protagonismo territorial de la residencia secundaria. 5. Profundos cambios en la morfología de los asentamientos: núcleos tradicionales, ensanches, urbanizaciones y diseminado. 6. Articulación funcional del Valle del Tiétar y los núcleos rectores del territorio. 7. Conclusión. 8. Bibliografía y documentación de referencia

\section{Organización político administrativa y gobierno del territorio}

El municipio, unidad de gestión administrativa más cercana al ciudadano, herencia de las dinámicas históricas de organización del territorio a lo largo de la historia y de la reforma administrativa de Javier de Burgos en la primera mitad del siglo XIX, cuando España era un país rural que apenas había iniciado el proceso de industrialización y urbanización, hoy tiene múltiples dificultades para ser un nivel administrativo eficiente cuando el $80 \%$ de la población vive en ciudades, una parte muy importante en áreas metropolitana y regiones urbanas, y 3.920 municipios, de un total de 8.125, tienen menos de 501 habitantes (INE,2016), un umbral de mínimos para mantener los servicios y equipamientos básicos que impidan el vaciamiento demográfico (FEMP, 2017). Tal como han resaltado Jesús Burgueño y Montserrat Guerrero, en un riguroso estudio de caracterización geográfica del mapa municipal, las comunidades autónomas no han aprovechado sus competencias para reformarlo y configurar ámbitos administrativos acordes con las nuevas realidades territoriales (Burgueño y 
Guerrero, 2014). En el caso de Castilla y León, con una superficie de $94.227 \mathrm{Km} 2$, 2.447.519 habitantes y 2.248 municipios, la situación es realmente crítica dado que, en 2016 , de un total de 2.248 municipios, 1.677 , el 74,60\%, están por debajo de los 501 habitantes y, de ellos, 666 no alcanzan los 101 habitantes.

A diferencia de Comunidades Autónomas como Cataluña (Ley 27/1987) y Aragón (Ley 8/1996) que, con un mayor o menor nivel de competencias, han establecido una organización comarcal de su territorio (Burgueño, 2001), Castilla y León, a pesar de ser un territorio extenso, de escasa y envejecida población, así como de una acusada atomización municipal (Martín; Hortelano; Plaza, 2007), no cuenta con una mapa comarcal institucional, solo El Bierzo, por su singularidad geográfica e histórica, tiene reconocido un estatus comarcal diferenciado (Ley 1/1991). El sistema de poblamiento castellano-leonés se caracteriza por la concentración de la población en las ciudades y una profunda despoblación rural, de ahí que el mapa municipal resulte disfuncional y ello a pesar de que de los 2.803 municipios existentes 1950 se ha pasado a 2248 en la actualidad (Martínez y Delgado, 2013). El debate sobre la articulación comarcal del territorio regional lleva tiempo abierto, en realidad desde el mismo momento de creación de la Comunidad Autónoma, porque ya en 1985, por encargo de la Junta, se realiza un Estudio y Propuesta de Comarcalización de Castilla y León (Junta Castilla y León, 1985). Desde esa fecha, si bien es cierto que la escala intermedia, comarca en unos casos y área funcional en otros, se ha utilizado en la ordenación del territorio y en la prestación de servicios, nunca son entendidas como circunscripciones administrativas (Santos y Peiret, 2001).

La "sacralización" de los límites autonómicos, provinciales y municipales está dificultando la creación de entidades de gestión, áreas metropolitanas en las zonas urbanas y comarcas en las zonas rurales, que posibiliten un gobierno y gestión del territorio acorde con las diversas realidades y dinámicas geográficas. Resulta urgente revisar en profundidad el modelo de gobierno del territorio rural castellano-leonés, algo que, de forma tímida y solo en lo referente a la organización de los servicios, plantea de una forma poco adecuada (Figura 1), desde nuestro punto de vista, la Ley de Ordenación, Servicios y Gobierno del Territorio de Castilla y León (BOE, Ley 7/2013), sin abordar el problema político de la organización territorial provincial que, tal como se planteó en las campañas electorales de 2015 y 2016, tanto en las elecciones generales como en las autonómicas, implicaría la supresión de las diputaciones provinciales.

Los debates políticos, con frecuencia, se alejan de las realidades territoriales y sociales, lo cual propicia un distanciamiento entre la ciudadanía y la clase política, planteándose, en ocasiones, reformas administrativas que se alejan de las realidades funcionales del territorio. La reforma de los mapas políticos, sea a escala de los estados, comunidades autónomas, provincias o municipios, siempre es una tarea ardua y conflictiva que solo será posible abordar con un conociendo en profundidad de las realidades geográficas de los ámbitos territoriales que se quieren reorganizar. En este sentido, este artículo persigue explicar el modelo de organización y la estructura funcional del Valle del Tiétar Abulense, un territorio periférico de Castilla y León, con relaciones y dependencias funcionales de las comunidades autónomas de Madrid, 
Castilla-La Mancha y Extremadura, evidenciando con claridad que las realidades sociales y funcionales saltan siempre por encima de la organización políticoadministrativa del territorio, tal y como se puso de manifiesto en los trabajos de la "Estrategia de Desarrollo Territorial Sostenible del Valle del Tiétar Abulense ${ }^{3}$ (Troitiño; Troitiño, 2016).

Figura 1. Mapa Unidades Básicas de Ordenación y Servicios del Territorio. Provincia de Ávila.

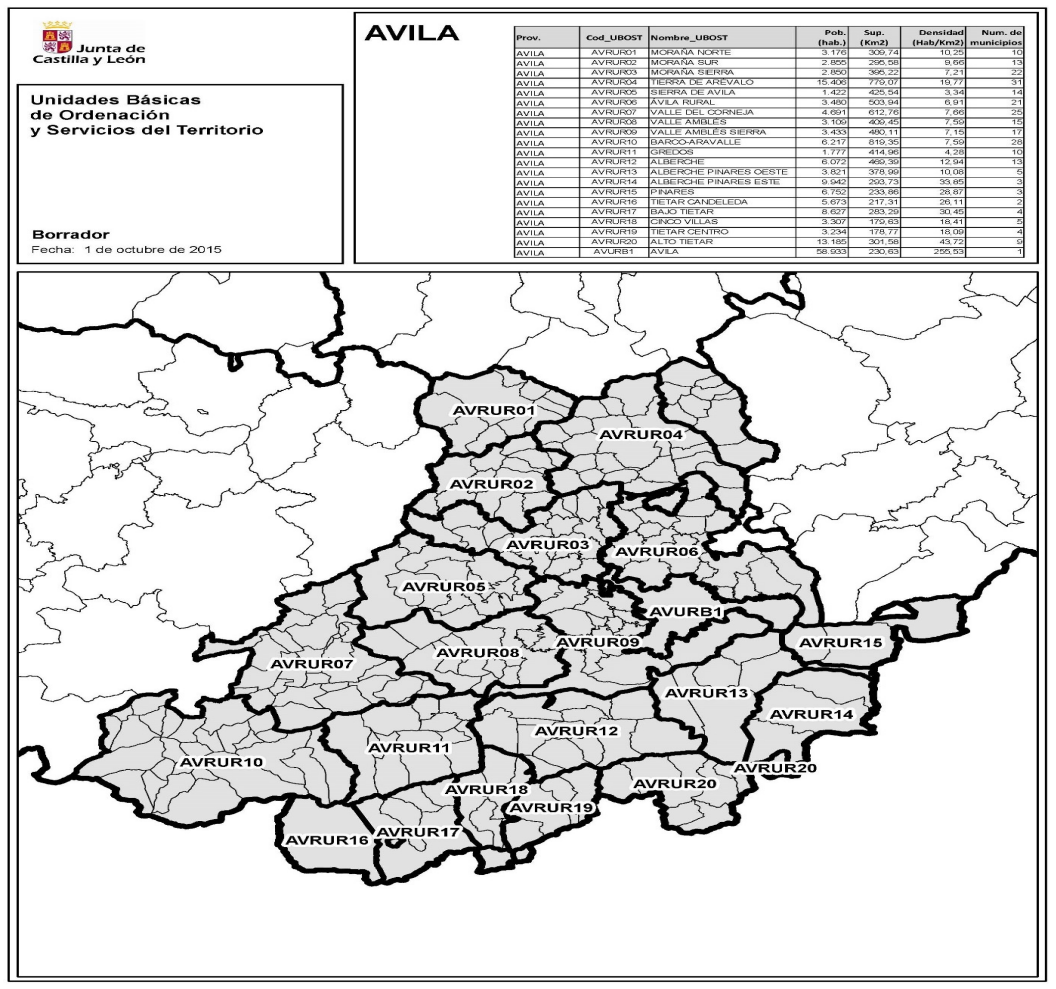

Fuente: Junta de Castilla y León, 2015

\footnotetext{
${ }^{3}$ El equipo técnico del proyecto estuvo integrado por: Miguel Ángel Troitiño Vinuesa (director), Manuel de la Calle, María García, Javier de Marcos, Gustavo Serrano y Libertad Troitiño, de la Universidad Complutense de Madrid; Luis Alfonso Hortelano, Isabel Martín y Miguel Herrero de la universidad de Salamanca; Fernando Martín de la universidad Autónoma de Madrid; Isabel de la Fuente y Lourdes Garro, profesoras de enseñanza media; Antonio Encinar y Enrique Fernández de la Diputación de Ávila; Nicolás González de la Junta de Castilla y León y Gonzalo Martín de la Institución Gran Duque de Alba. La dirección y coordinación institucional fue desarrollada por Carmelo Luís López y Jesús Reyes de la Institución gran Duque de Alba). Los trabajos se desarrollaron entre 2004 y 2008. Esta Estrategia de Desarrollo, al igual que ha ocurrido en otros muchos casos, se quedó en un documento técnico sin ningún tipo de aplicación.
} 


\section{Organización político-administrativa del Valle del Tiétar}

El Valle del Tiétar, situado en la zona de contacto entre cuatro Comunidades Autónomas, Castilla y León, Extremadura, Castilla La Mancha y Madrid, se configura como una comarca en la periferia Sur de Castilla y León (Figura 2). Esta singularidad la reconocen diversos estudios geográficos e históricos (Brandis y Troitiño, 1977; Troitiño, 1990; Tejero, 1990), la comarcalización agraria del Ministerio de Agricultura, Alimentación y Medio Ambiente (2014), los instrumentos autonómicos de ordenación del territorio, caso de las Directrices de Ordenación del Territorio de Castilla y León, al diferenciar el Área Funcional del Tiétar con Arenas de San Pedro como centro rector (Junta de Castilla y León, 1996) o el Boletín Turístico de la provincia de Ávila (Melgosa y Troitiño, 2015). La superficie de la comarca, $1.159 \mathrm{Km} 2$, representa el $14,39 \%$ del conjunto provincial y su población, 33.091 habitantes (2016), el 20,36 \% (Tabla 1). La comarca está constituida por 24 municipios cuyas características y entidad, tanto demográfica como territorial, guardan estrechas relaciones con las funciones que han ido adquiriendo o perdiendo los diferentes núcleos a lo largo del tiempo; en este sentido, núcleos como Candeleda, Mombeltrán, Pedro Bernardo o La Adrada han perdido significación, mientras que otros como Piedralaves o Sotillo de la Adrada la han ganado.

Figura 2. Encuadre territorial. El Valle del Tiétar el contexto nacional y regional.

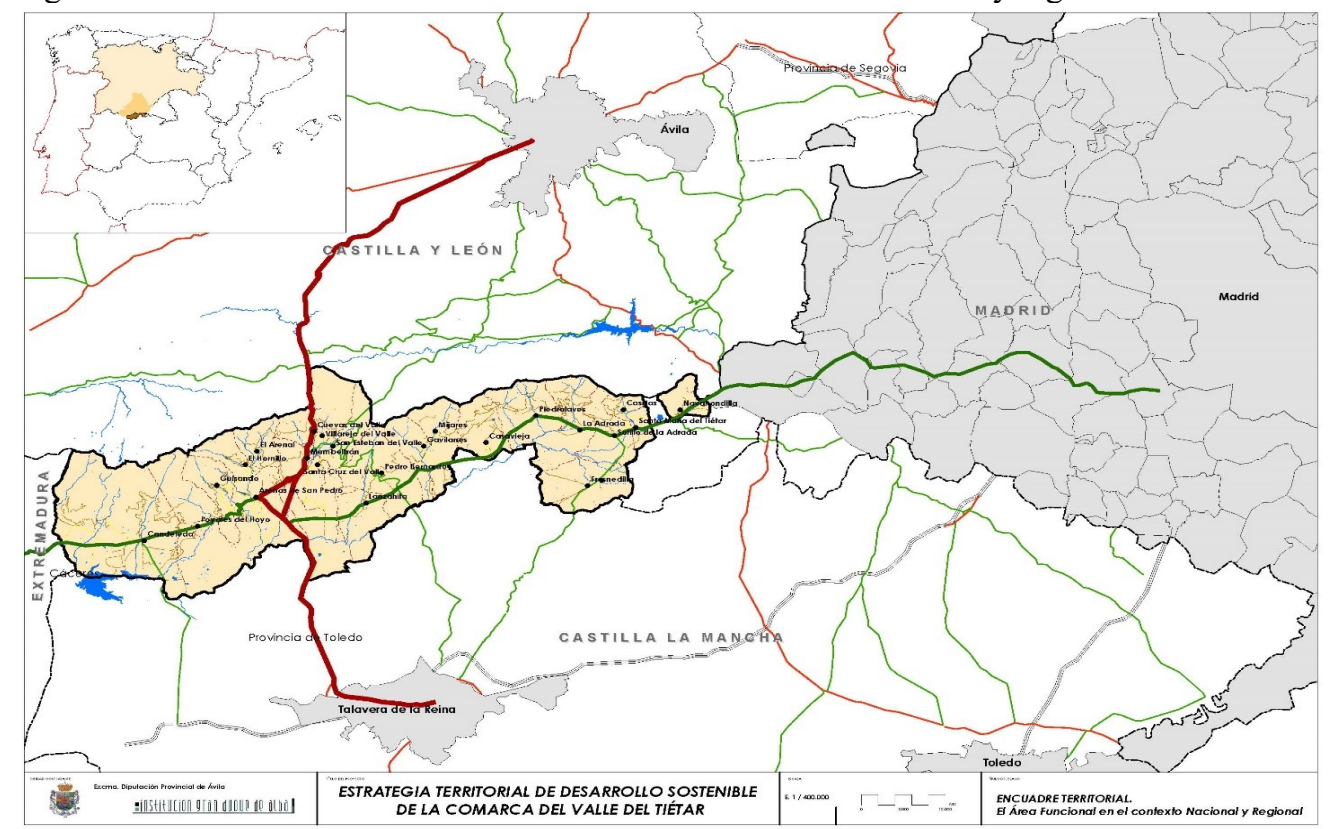

Fuente: Estrategia territorial de desarrollo sostenible de la comarca del Valle del Tiétar. Diputación provincial de Ávila. 2008 
Tabla 1. Estructura Municipal del Valle del Tiétar ${ }^{4}$

\begin{tabular}{|c|c|c|c|c|}
\hline Municipio & $\begin{array}{c}\text { Superficie } \\
\mathbf{K m}^{2}\end{array}$ & $\begin{array}{c}\text { Población } \\
\text { (2016) }\end{array}$ & $\begin{array}{c}\text { Recibos IBI } \\
\text { (2011) }\end{array}$ & $\begin{array}{c}\text { Viviendas } \\
2^{2001^{1}} \\
\end{array}$ \\
\hline La Adrada & 59 & 2.619 & 6.376 & 3.627 \\
\hline El Arenal & 27 & 998 & 1.634 & 1.206 \\
\hline Arenas de San Pedro & 195 & 6.615 & 7.766 & 4.910 \\
\hline Candeleda & 214 & 5.034 & 6.929 & 4.185 \\
\hline Casavieja & 39 & 1.479 & 3.222 & 2.000 \\
\hline Casillas & 12 & 672 & 1.372 & 1.100 \\
\hline Cuevas del Valle & 19 & 507 & 943 & 729 \\
\hline Fresnedilla & 25 & 122 & 359 & 177 \\
\hline Gavilanes & 29 & 615 & 1.144 & 841 \\
\hline Guisando & 37 & 534 & 932 & 686 \\
\hline $\begin{array}{l}\text { Higuera de las } \\
\text { Dueñas }\end{array}$ & 35 & 297 & 735 & 485 \\
\hline El Hornillo & 24 & 311 & 645 & 370 \\
\hline Lanzahita & 34 & 855 & 1.456 & 919 \\
\hline Mijares & 47 & 755 & 1.562 & 1.001 \\
\hline Mombeltrán & 50 & 1.111 & 1.615 & 980 \\
\hline Navahondilla & 22 & 324 & 922 & 660 \\
\hline Pedro Bernardo & 69 & 892 & 2.165 & 2.008 \\
\hline Piedralaves & 55 & 2.130 & 3.753 & 2.351 \\
\hline Poyales del Hoyo & 3 & 556 & 908 & 799 \\
\hline Santa Cruz del Valle & 30 & 379 & 742 & 538 \\
\hline San Esteban del Valle & 37 & 791 & 1.050 & 967 \\
\hline $\begin{array}{l}\text { Santa María del } \\
\text { Tiétar }\end{array}$ & 12 & 483 & 1.605 & 1.066 \\
\hline Sotillo de la Adrada & 43 & 4.621 & 7.643 & 4.034 \\
\hline Villarejo del Valle & 42 & 391 & 745 & 561 \\
\hline TOTAL & 1.159 & 33.091 & 56.223 & 36.200 \\
\hline
\end{tabular}

Fuente: Caja España. Datos Económicos y Sociales de las Unidades Territoriales de España. 2012. INE. Censo Viviendas 2001 y Padrón 2016.

\footnotetext{
${ }^{4}$ Se toma de referencia el censo 2001 ya que el de 2011 el INE no proporciona información de viviendas para los municipios menores de 1000 habitantes.
} 
El tamaño de los municipios ofrece contrastes llamativos y significativos, el más pequeño es Poyales del Hoyo, $3 \mathrm{Km}^{2}$, por la singularidad de su proceso autonómico en el siglo XVII, al que se oponían tanto Candeleda como Arenas de San Pedro (Troitiño, 1999, pp.160-168) y el mayor es Candeleda, con $214 \mathrm{Km}^{2}$. A nivel general, en términos de superficie, se pueden diferenciar cuatro categorías de municipios:

1)Municipios grandes: Candeleda $214 \mathrm{Km}^{2}$ y Arenas de San Pedro $195 \mathrm{Km}^{2}$. En ambos casos se corresponden con viejas cabeceras de señorío, villas desde 1393 (Luis López, 1993), muy celosas del control territorial, tal como evidencian la pervivencia del Proindiviso entre Candeleda y Arenas y el conflicto de términos con Poyales del Hoyo (Calvi y Podii, 1988).

2)Municipios de tipo medio, entre 35 y $70 \mathrm{Km}^{2}$, son La Adrada, Casavieja, Guisando, Higuera de las Dueñas, Mijares, Mombeltrán, Pedro Bernardo, Piedralaves, San Esteban, Sotillo y Villarejo. Aquí hay tanto antiguas cabeceras de señoríos, La Adrada, Mombeltrán e Higuera de las Dueñas, como aldeas que fueron logrando su autonomía a partir del siglo XVII.

3)Municipios pequeños, entre 20 y $35 \mathrm{Km}^{2}$, son El Arenal, Fresnedilla, Gavilanes, El Hornillo, Lanzahita, Navahondilla y Santa Cruz.

Municipios muy pequeños, entre 20 y $3 \mathrm{Km}^{2}$. Son Casillas, Cuevas del Valle, Santa María del Tiétar y Poyales del Hoyo con sólo $3 \mathrm{Km}^{2}$.

Las jerarquías demográficas guardan relación con el tamaño de los municipios y su papel histórico, pero no de forma absoluta. Así, Arenas es el segundo municipio en superficie y el primero en población, Sotillo de la Adrada es el octavo en superficie y el tercero en población y Pedro Bernardo que es el tercero en superficie y sólo es noveno en población. La Adrada, cabecera histórica y término de tipo medio, tiene menos población que Sotillo de la Adrada, su antigua aldea y con un término más pequeño. El caso extremo de desajuste entre población y territorio se evidencia en Poyales del Hoyo (Figura 3).

Si utilizamos otros indicadores como los recibos del Impuesto de Bienes Inmuebles, el ranking de municipios varía, así los cinco primeros son Arenas, Sotillo, La Adrada, Candeleda y Piedralaves; los cinco últimos son Fresnedilla, El Hornillo, Higuera de las Dueñas, Santa Cruz del Valle y Villarejo. En términos urbanísticos, municipios como Navahondilla, La Adrada, Casavieja, Piedralaves o Santa María del Tiétar tienen un mayor protagonismo que territorial o demográfico. 
Figura 3. Organización político-administrativa.

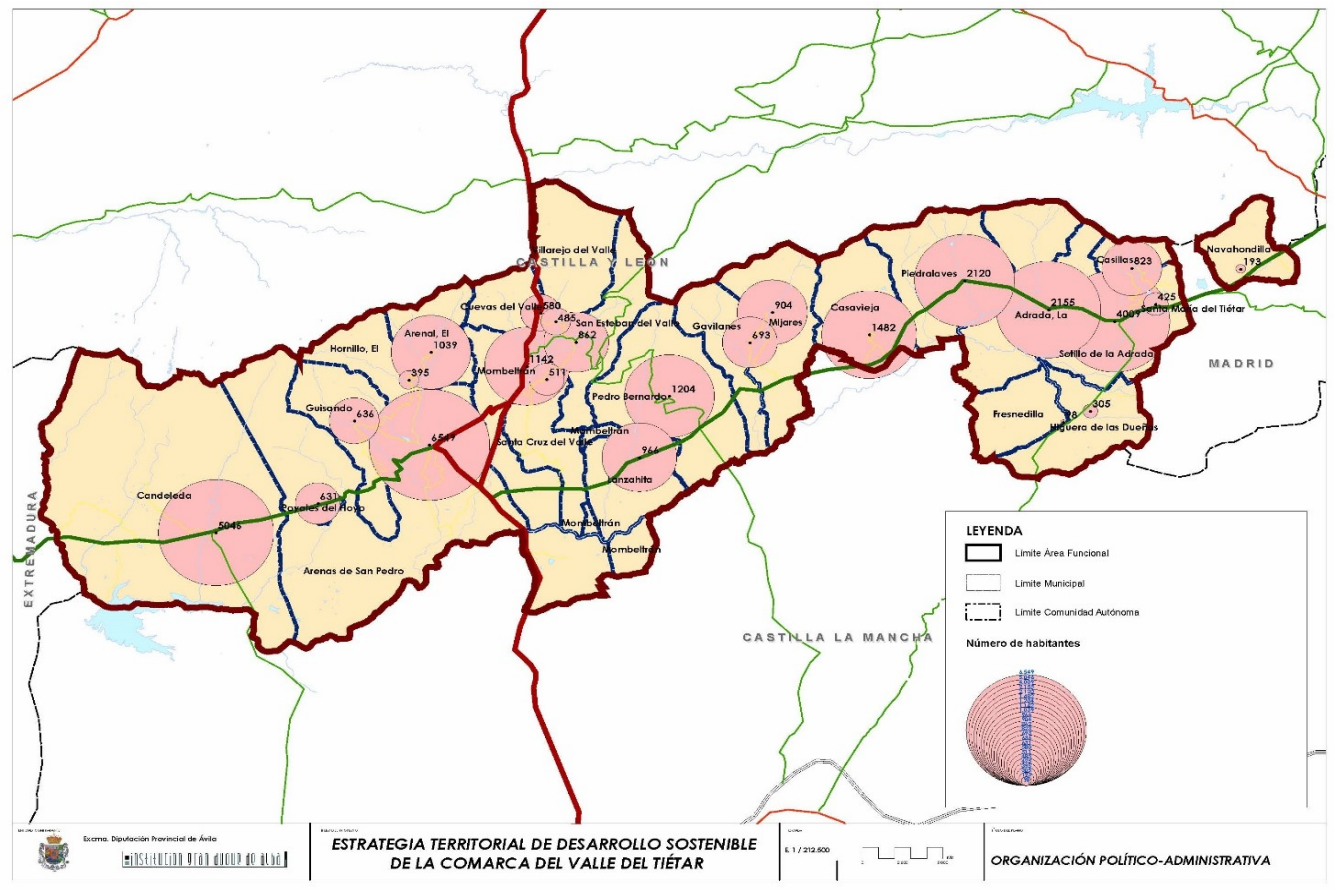

Fuente: Estrategia territorial de desarrollo sostenible de la comarca del Valle del Tiétar. Diputación provincial de Ávila. 2008

En suma, una articulación municipal fragmentada, propia de ciclo preindustrial, donde, si bien se reconoce la entidad geográfica comarcal por su peculiar situación geográfica, entre el río Tiétar y las cumbres de Gredos, no existe una realidad funcional y administrativa propiamente comarcal, tal como se evidenció con claridad en el estudio "Estrategia de Desarrollo Territorial Sostenible del Valle del Tiétar" (Troitiño, 2008).

\section{Estructura y características básicas del poblamiento}

La estructura actual del poblamiento de la comarca es, por un lado, el resultado de un largo proceso de evolución histórica que arranca en la Edad Media (Troitiño, 1999) y, por otro, de las transformaciones recientes, vinculadas fundamentalmente con el fuerte crecimiento de las urbanizaciones de residencia secundaria, la renovación y expansión de los cascos de los pueblos y el abandono o transformación de los antiguos asentamientos rurales relacionados con las explotaciones agrarias o ganaderas. 
El modelo tradicional guardaba bastante relación con las potencialidades ecológicas del territorio y se articulaba a partir de los núcleos cabecera, generalmente las villas más antiguas, ubicados en el fondo del valle o en las laderas bajas, núcleos de tipo medio en las laderas y valles más abiertos, pequeños núcleos en valles interiores más estrechos o territorios con menores recursos y aldeas dependientes de los núcleos más potentes, casos de La Parra, Hontanares, Las Majadas, Ramacastañas o La Higuera. A ello se unía un poblamiento diverso y rico, distribuido por el fondo del valle, las laderas y las cumbres, en relación con los diversos tipos de explotaciones agrícolas, ganaderas o forestales, en unos casos con ocupación permanente $\mathrm{y}$ en otros sólo durante el tiempo que duraban las faenas agrícolas (chozos, majadas, casas de labor, molinos, secaderos, etc.).

Tabla 2. Distribución de Unidades Urbanas, Parcelas y Solares del Valle del Tiétar.

\begin{tabular}{|c|c|c|c|c|}
\hline Municipio & $\begin{array}{l}\text { Superficie catastral } \\
\text { urbana (has).2010 }\end{array}$ & Unidades urbanas & $\begin{array}{l}\text { Parcelas urbanas } \\
\text { Edificadas }\end{array}$ & Solares \\
\hline La Adrada & 381 & 6.512 & 2.770 & 1.229 \\
\hline El Arenal & 51 & 1.661 & 1.102 & 495 \\
\hline Arenas de San Pedro & 197 & 7.805 & 3.390 & 565 \\
\hline Candeleda & 193 & 7.086 & 3.154 & 872 \\
\hline Casavieja & 112 & 3.156 & 2.017 & 663 \\
\hline Casillas & 12 & 1.395 & 884 & 137 \\
\hline Cuevas del Valle & 31 & 1.023 & 580 & 203 \\
\hline Fresnedilla & 14 & 375 & 282 & 81 \\
\hline Gavilanes & 25 & 1.196 & 838 & 198 \\
\hline Guisando & 33 & 972 & 566 & 215 \\
\hline Higuera de las Dueñas & 50 & 775 & 559 & 150 \\
\hline El Hornillo & 12 & 709 & 368 & 159 \\
\hline Lanzahita & 64 & 1.597 & 968 & 351 \\
\hline Mijares & 38 & 1.628 & 790 & 352 \\
\hline Mombeltrán & 61 & 1.673 & 939 & 300 \\
\hline Navahondilla & 67 & 933 & 696 & 164 \\
\hline Pedro Bernardo & 48 & 2.378 & 1.438 & 386 \\
\hline Piedralaves & 193 & 3.912 & 1.937 & 815 \\
\hline Poyales del Hoyo & 18 & 934 & 730 & 55 \\
\hline Santa Cruz del Valle & 34 & 808 & 549 & 134 \\
\hline San Esteban del Valle & 13 & 1.114 & 867 & 70 \\
\hline Santa María del Tiétar & 43 & 1.641 & 815 & 121 \\
\hline Sotillo de la Adrada & 298 & 7.777 & 3.132 & 1.991 \\
\hline Villarejo del Valle & 22 & 810 & 475 & 220 \\
\hline TOTAL & 2.100 & 58.486 & 29.846 & 9.866 \\
\hline
\end{tabular}

Fuente: Caja España. Datos Económicos y Sociales de las Unidades Territoriales de España. 2012. 
Los cambios funcionales del territorio y el paso de unas economías agrarias a otras cada vez más fundamentadas en el sector servicios, especialmente en las actividades turístico/recreativas (Calle y García, 2006; Melgosa y Troitiño, 2015), han introducido, en estrecha relación con la influencia cada vez mayor de la región urbana de Madrid y la expansión de la vivienda secundaria, cambios importantes en la estructura del poblamiento $\mathrm{y}$, especialmente, en el significado territorial de los espacios construidos (Solís, 2011). En efecto, los pueblos se han transformado, han crecido de forma significativa y, además, se han configurado áreas de urbanizaciones dispersas, fundamentalmente en la zona oriental de la comarca.

La superficie urbana catastrada es de 2.010 Has y su distribución por municipios evidencia que los de mayor superficie catastral urbana se localizan en la zona oriental del Valle. Así, el municipio con mayor superficie catastral urbana es La Adrada (381 Has), seguido de Sotillo (298Has), Arenas de San Pedro (197 Has), Candeleda (193 Has) y Piedralaves (193 Has). Existen acusados desajustes entre la superficie catastral urbana y la entidad demográfica o económica de los municipios, aspecto evidente en Casavieja, Lanzahita, Santa María del Tiétar y especialmente en Navahondilla.

La construcción y, en general, la actividad inmobiliaria se convirtieron, hasta el comienzo de la crisis de 2008, en una de las claves de la dinámica económica y territorial de la comarca y, también, en un importante foco de impactos medioambientales y paisajísticos (Troitiño, 1997). El territorio ha ido siendo invadido por la residencia secundaria y los entornos de los pueblos, antiguas zonas de huertos, se han convertido en terrenos urbanísticos expectantes, recogidos en el catastro de urbana como solares.

La función del Valle del Tiétar como territorio de residencias secundarias se ha ido reforzando durante las últimas décadas y buena prueba de ello es la existencia de 58.486 unidades urbanas, cifra muy superior al número de habitantes. Tienen por encima de las seis mil unidades, Arenas, Sotillo, Candeleda y la Adrada. En general, las unidades urbanas, al igual que los recibos del IBI, guardan relación, por un lado, con la entidad demográfica de los municipios y, por otro, con la mayor o menor presencia de las viviendas secundarias, especialmente evidente en la cabecera del Tiétar y en Navahondilla.

La presión de la actividad edificatoria se evidencia también en el elevado número de parcelas urbanas edificadas, un total de 29.846. Nuevamente, su distribución territorial guarda relación tanto con la entidad demográfica de los municipios como con la mayor o menor presencia de la vivienda secundaria. Así Arenas, Candeleda, Sotillo, La Adrada, Casavieja y Piedralaves concentran el $54,17 \%$ de las parcelas edificadas. Resalta que municipios con débil entidad demográfica, casos de Navahondilla o Santa María del Tiétar, tengan elevado número de parcelas edificadas.

Las expectativas de crecimiento urbanístico se reflejan con claridad en la elevada cifra de solares que registran los catastros de urbana, nada más y nada menos que 9.866. Su distribución territorial se relaciona con las previsiones o deseos de construcción de los municipios y con su entidad demográfica, así Sotillo de la Adrada se acerca a los 2.000 solares, la Adrada tiene 1.229 y se aproximan a los 1.000 , Candeleda y Piedralaves. Las expectativas de crecimiento residencial han sido 
elevadas en toda la comarca pues municipios con núcleos de escasa entidad cuentan con un elevado número de solares.

\section{Crecimiento explosivo del parque edificado y protagonismo territorial de la residencia secundaria}

El parque edificado de la comarca ha crecido de forma espectacular en los últimos años, así el número de edifícios pasó de 13.969 en 1970 a 26.169 en el año 2001, superando los 30.000 en la actualidad. Este incremento se ha debido fundamentalmente a la expansión del parque residencial que ha aumentado fuertemente durante las últimas décadas: de 15.360 viviendas en 1970 se pasó a las 36.200 en $2001^{5}$. Este incremento es más llamativo si tenemos presente que en ese mismo periodo la población residente disminuyó, de 38.241 habitantes a 32.571.

En cifras absolutas, los crecimientos más fuertes corresponden a los municipios con mayor entidad demográfica y a aquellos otros donde ha sido más fuerte la expansión de la vivienda secundaria, casos, por un lado, de Arenas y Candeleda, y, por otro, de La Adrada, Sotillo, Casavieja o Piedralaves. El análisis por municipios evidencia, junto a crecimientos generalizados, importantes contrastes territoriales y, especialmente, el mayor o menor grado de penetración de la residencia secundaria.

El gran motor de la urbanización ha sido, sin duda, el crecimiento del parque de edificios residenciales. La dinámica edificatoria tiene un marcado carácter expansivo, así en el intercensal 1991-2001 se construyeron un total de 2.764 edificios destinados a viviendas, lo cual significaba el $10,56 \%$ del parque edificado existente en el año 2001 (Tabla 3). La dinámica expansiva está territorialmente muy generalizada y resalta como en cinco municipios se construyeron por encima de los 200 edificios (Candeleda, Arenas, Sotillo de la Adrada, La Adrada y Piedralaves).

El parque residencial y, especialmente, la vivienda secundaria ha crecido de forma explosiva. En el año 2001 existían un total 36.200 viviendas, 12.869 principales, 18.793 secundarias, 4.133 vacías y 340 de otro tipo. Si comparamos con la situación de 1970 nos encontramos que las viviendas principales apenas han crecido, de 11.068 a 12.869 , mientras que se ha producido una explosión de las secundarias, de 2.360 a 18.793, y las vacías y de otro tipo se han más que duplicado, de 1.885 a 4.479 .

\footnotetext{
${ }^{5}$ Se toman de referencia los datos de 2001, ya que, lamentablemente, el censo de viviendas de 2011 solo proporciona información desagregada de los municipios con más de 2.000 , rompiendo series estadísticas históricas.
} 
Tabla 3. Evolución de las viviendas secundarias (1970-2001), índices de especialización ${ }^{1}$ y densidad $^{6}$

\begin{tabular}{|c|c|c|c|c|}
\hline \multirow[b]{2}{*}{ MUNICIPIO } & \multicolumn{4}{|c|}{ VIVIENDAS SECUNDARIAS } \\
\hline & 1970 & 2001 & Índice & $\begin{array}{l}\text { Densidad } \\
\text { (viv. } / \mathbf{k m}^{2} \text { ) }\end{array}$ \\
\hline La Adrada & 198 & 2.608 & 3,00 & 44,20 \\
\hline El Arenal & 75 & 742 & 1,96 & 27,48 \\
\hline Arenas de San Pedro & 269 & 1.366 & 0,62 & 7,00 \\
\hline Candeleda & 15 & 1.805 & 0,96 & 8,43 \\
\hline Casavieja & 41 & 1.167 & 1,79 & 29,92 \\
\hline Casillas & 44 & 612 & 1,66 & 51,00 \\
\hline Cuevas del Valle & 61 & 337 & 1,33 & 17,74 \\
\hline Fresnedilla & 27 & 118 & 2,36 & 4,72 \\
\hline Gavilanes & 35 & 485 & 1,66 & 16,72 \\
\hline Guisando & 25 & 283 & 1,08 & 7,65 \\
\hline Higuera de las Dueñas & 73 & 331 & 2,52 & 9,46 \\
\hline El Hornillo & 26 & 175 & 1,04 & 7,29 \\
\hline Lanzahita & 58 & 542 & 1,47 & 15,94 \\
\hline Mijares & 64 & 509 & 1,43 & 10,82 \\
\hline Mombeltrán & 47 & 515 & 1,13 & 10,03 \\
\hline Navahondilla & 37 & 573 & 8,43 & 26,00 \\
\hline Pedro Bernardo & 232 & 1.226 & 2,20 & 14,57 \\
\hline Piedralaves & 339 & 1.296 & 1,61 & 23,56 \\
\hline Poyales del Hoyo & 66 & 440 & 1,61 & 146,47 \\
\hline Santa Cruz del Valle & 76 & 203 & 0,89 & 5,49 \\
\hline San Esteban del Valle & 60 & 556 & 1,50 & 18,53 \\
\hline Santa María del Tiétar & 240 & 808 & 4,61 & 67,33 \\
\hline Sotillo de la Adrada & 207 & 1.738 & 1,27 & 40,42 \\
\hline Villarejo del Valle & 45 & 353 & 1,83 & 8,40 \\
\hline TOTAL & 2.360 & 18.793 & 1,46 & 16,21 \\
\hline
\end{tabular}

Fuente: INE. Censos de Viviendas. 1970-2001

La distribución del parque de viviendas principales guarda proporcionalidad con la entidad demográfica de los diferentes municipios $\mathrm{y}$, por tanto, el protagonismo corresponde a los mayores, y los incrementos a aquellos que tienen dinámicas demográficas positivas: Arenas, Candeleda, Sotillo, La Adrada, Piedralaves y Casavieja. Las viviendas secundarias, las verdaderas protagonistas del cambio, tienen una fuerte presencia en todos los municipios y, con la excepción de Arenas y

\footnotetext{
6 Índice de especialización: relación viviendas secundarias por viviendas principales.
} 
Candeleda, los de mayor entidad demográfica, siempre superan en número a las viviendas principales (Figura 4).

Las viviendas han conocido un crecimiento espectacular, un $769 \%$ en 31 años, y, además, se han difundido territorialmente. Así mientras en 1970 se concentraban en la cabecera del Valle, en el 2001 ya se habían extendido por toda la comarca. Los incrementos más espectaculares en términos porcentuales corresponden a Candeleda (en el oeste de la comarca), Casavieja, Navahondilla, Casillas, Gavilanes, Guisando y El Arenal.

Figura 4: Valle del Tiétar: Distribución municipal de las viviendas secundarias

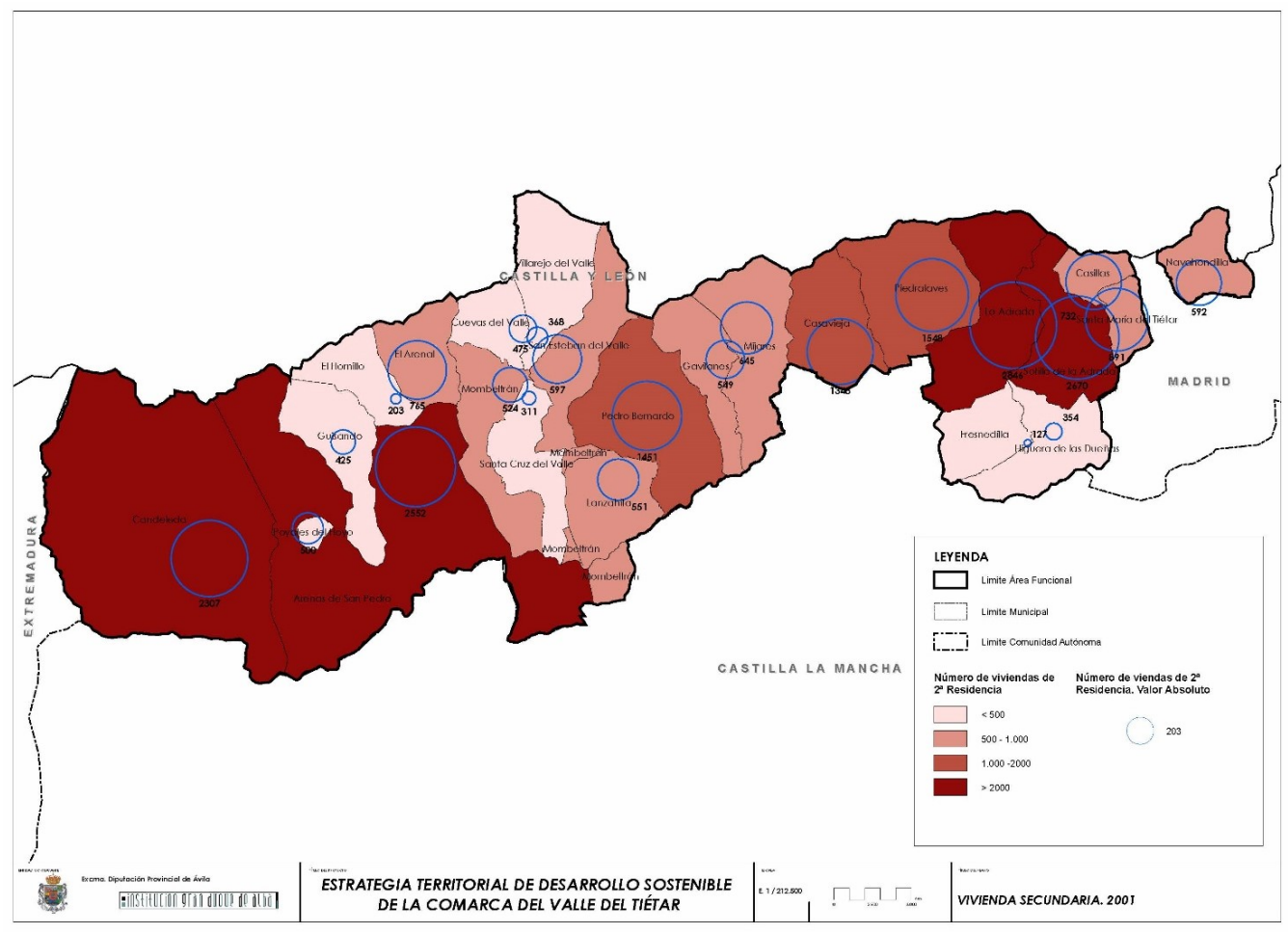

Fuente: Estrategia territorial de desarrollo sostenible de la comarca del Valle del Tiétar. Diputación provincial de Ávila. 2008

El índice de especialización (viviendas secundarias/ viviendas principales) refleja con mayor claridad el grado de protagonismo de este tipo de viviendas en los diversos municipios. Navahondilla tiene muy alta especialización $(8,43)$; un grado alto $(2$ a 5$)$ corresponde Santa María $(4,61)$, Higuera de las Dueñas y Fresnedilla; un grado medio (1-2) a El Arenal, Casaviejas, Casillas, Gavilanes, Lanzahita, Mijares, Guisando, El Hornillo, Mombeltrán, Piedralaves, Poyales, Sotillo y Villarejo; un grado bajo (inferior a uno) Arenas, Candeleda, San Esteban del Valle y Santa Cruz del Valle. La 
densidad refleja, en mayor o menor medida, el nivel de presión que la vivienda secundaria ejerce sobre el territorio, correspondiendo los valores más altos a Poyales del Hoyo, por su singular conformación municipal, Santa María del Tiétar, Casillas, La Adrada y Sotillo de la Adrada, por encima de 40 viviendas secundarias por $\mathrm{Km}^{2}$.

El protagonismo de la actividad inmobiliaria se evidencia con claridad al comprobar que había 56.223 recibos en el Impuesto de Bienes Inmuebles (2010), cuyo valor catastral ascendía a 1.534,4 millones de euros. Los recibos del IBI y los valores catastrales, aunque con la cautela de los problemas de actualización, también sirven para medir el rango urbanístico de los diversos municipios. El primer lugar corresponde a Arenas de San Pedro con 7.776 recibos y 196,3 millones de euros de valor catastral, a corta distancia se encuentran Sotillo de la Adrada, Candeleda y La Adrada.

En un segundo nivel, con cerca de 3.500 recibos se encuentran Piedralaves y Casavieja. Todos los municipios superan, con la excepción de Fresnedilla, los 500 recibos de IBI y siempre su número es superior al de habitantes. Esta situación pone de manifiesto como las finanzas de los ayuntamientos dependen, en buena medida, de los ingresos procedentes del IBI, ya que los que tradicionalmente venían proporcionando la explotación de maderas, resinas y pastos han quedado reducidos a su mínima expresión.

El poblamiento del Tiétar, con la excepción de pequeñas áreas en las afueras de los núcleos o en ámbitos de actividad turística/recreativa, está fuertemente marcado por los tejidos residenciales, ya sea de los núcleos tradicionales o de las urbanizaciones. Resulta llamativa la ausencia, con la excepción de Sotillo de la Adrada y, en menor medida, de Arenas de San Pedro, de polígonos de actividad económica claramente diferenciados.

\section{Profundos cambios en la morfología de los asentamientos: núcleos tradicionales, ensanches, urbanizaciones y diseminado}

Durante las últimas décadas, de forma paralela a los cambios socioeconómicos y a la expansión de la vivienda secundaria y de las actividades de ocio, se ha producido un cambio profundo en las formas y en las tipologías de los asentamientos, así los núcleos tradicionales se han visto profundamente transformados (Arenillas y Burgués, 1990) y, además, han cedido protagonismo territorial a las zonas de ensanche, las urbanizaciones y los diseminados. Según la ortoimagen del Valle del Tiétar de 2002, las superficies ocupadas por las edificaciones era de 1.332 Has (Figura 5). Y su distribución por tipologías era la siguiente: 283 Has correspondían a los núcleos 
tradicionales, 180 Has a las zonas de ensanche, 728 a las urbanizaciones y 141 a los asentamientos en diseminado ${ }^{7}$.

Figura 5. Valle del Tiétar: Estructura territorial del poblamiento

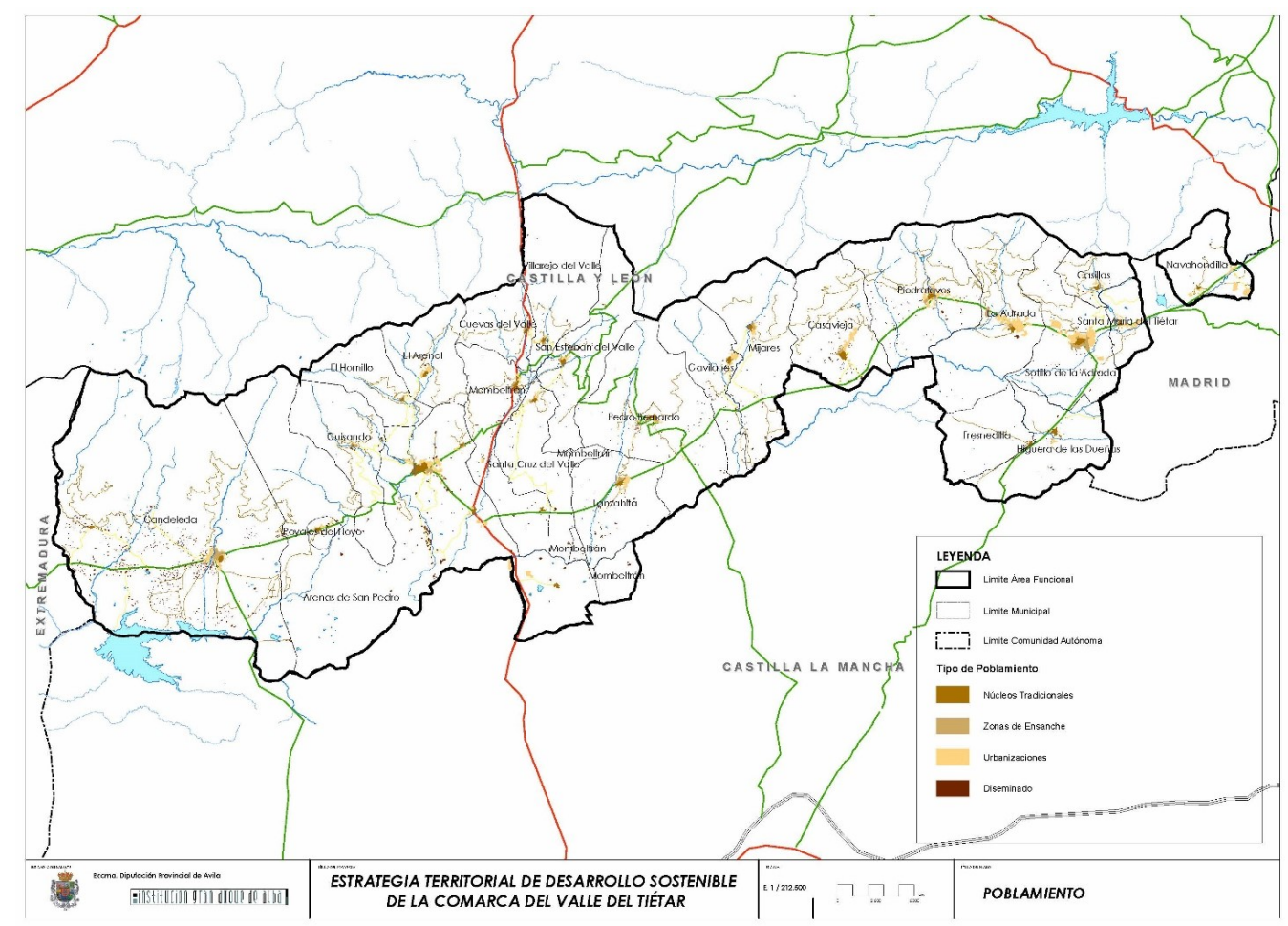

Fuente: Estrategia territorial de desarrollo sostenible de la comarca del Valle del Tiétar. Diputación provincial de Ávila. 2008

La superficie ocupada por las edificaciones era del 1,15\% del territorio comarcal, sin embargo existen acusados contrastes entre los municipios (Tabla 4). Los mayores niveles de ocupación de suelo por las edificaciones, sin considerar Poyales del Hoyo, corresponden a Sotillo de la Adrada (4,69\%), Santa María del Tiétar (3,25\%), Navahondilla (2,68\%) y La Adrada (2,14\%); con valores entre el 1 y el $2 \%$ de su término municipal están Casavieja, Piedralaves, Lanzahita, Casillas y Gavilanes y Arenas; los valores relativos más bajos corresponden a Fresnedilla, El Hornillo,

\footnotetext{
${ }^{7}$ Agradecemos a Gustavo Garro Serrano (geógrafo) el trabajo que llevó a cabo con la ortoimagen del Valle del Tiétar en el marco de los trabajos de la Estrategia de Desarrollo Territorial Sostenible.
} 
Guisando y Villarejo. Por lo general, con la excepción de Fresnedilla e Higuera de las Dueñas, por su menor atractivo paisajístico, son los municipios del sector oriental del Valle donde la presión urbanística sobre el territorio es más fuerte.

Tabla 4. Superficie ocupada por las edificaciones según tipología y municipios en 2002 (Has)

\begin{tabular}{|c|c|c|c|c|c|c|}
\hline MUNICIPIOS & $\begin{array}{c}\text { Sup. } \\
\text { Municipal }\end{array}$ & Sup. Edificaciones & Núcleo & Ensanche & Urbanizaciones & Diseminado \\
\hline Adrada, La & 5.877 & 125,8 & 9,5 & 15,0 & 97,2 & 4,1 \\
\hline Arenal, El & 2.691 & 24,4 & 9,1 & 13,2 & & 0,2 \\
\hline Arenas de San Pedro & 19.698 & 230,2 & 67,3 & 13.0 & 119,5 & 30,3 \\
\hline Candeleda & 21.292 & 134,1 & 15,8 & 28,4 & 43,8 & 45,9 \\
\hline Casavieja & 3.912 & 72,2 & 18,1 & 10,1 & 38,5 & 5,5 \\
\hline Casillas & 1.191 & 18,5 & 5,9 & 1,9 & 1,0 & 0.6 \\
\hline Cuevas del Valle & 1.925 & 18,4 & 5,3 & 2,9 & 9,6 & 0,5 \\
\hline Fresnedilla & 2.455 & 7,2 & 4,9 & 1,6 & 0.3 & 0.4 \\
\hline Gavilanes & 2.922 & 36,7 & 6,7 & 3,4 & 2,4 & 2,6 \\
\hline Guisando & 3.724 & 12,7 & 3,3 & 3,6 & 2,3 & 3,4 \\
\hline Higuera de las Dueñas & 3.520 & 20,6 & 11,4 & & 7,0 & 2,3 \\
\hline Hornillo, El & 2.408 & 7,8 & 4,4 & 2,6 & 0,5 & 9,2 \\
\hline Lanzahita & 3.340 & 46,7 & 11,2 & 8,0 & 23,8 & 3,7 \\
\hline Mijares & 4.709 & 33,0 & 10,0 & 4,4 & 14,1 & 4,6 \\
\hline Mombeltrán & 5.002 & 45,9 & 17,3 & 6,6 & 14,1 & 7,9 \\
\hline Navahondilla & 2.181 & 58,5 & 3,2 & & 54,3 & 1,0 \\
\hline Pedro Bernardo & 6.890 & 37,3 & 13,3 & 3,7 & 16,6 & 3,8 \\
\hline Piedralaves & 5.526 & 90.0 & 11,5 & 3,6 & 56,3 & 8,6 \\
\hline Poyales del Hoyo & 338 & 17,6 & 8,0 & & 7,0 & 2,6 \\
\hline San Esteban del Valle & 3.700 & 23,7 & 9,4 & 5,7 & 6,6 & 2,3 \\
\hline Santa Cruz del Valle & 2.971 & 16,9 & 4.0 & 4,4 & 4,9 & 3,4 \\
\hline Santa María del Tiétar & 1.100 & 38,6 & 4,1 & 3,2 & 3,1 & 0.6 \\
\hline Sotillo de la Adrada & 4.282 & 201 & 23,1 & 45,8 & 129,3 & 2,9 \\
\hline Villarejo del Valle & 4.159 & 14,2 & 5,5 & 2,4 & 5,0 & 1,2 \\
\hline Total & 115.920 & 13.319 & 282,6 . & 193,4 & 715,2 & 140,7 \\
\hline
\end{tabular}

Fuente: Explotación ortoimagen municipios del Valle del Tiétar. 2002. Estrategia Territorial Sostenible del Valle del Tiétar Abulense. 2008.

Los núcleos tradicionales, coincidentes con los cascos antiguos de los pueblos, ocupan 283 Has y su tamaño guarda proporcionalidad con el peso histórico de los diferentes núcleos, siendo los mayores Arenas de San Pedro, Sotillo de la Adrada, Candeleda, Casavieja, Mombeltrán y Pedro Bernardo. Un segundo nivel, con núcleos con un tamaño del orden de 10 Has, corresponde a Piedralaves, Lanzahita, La Adrada, 
El Arenal y San Esteban del Valle. Los núcleos más pequeños, como es lógico, corresponden a los municipios que históricamente tuvieron menor entidad demográfica, casos, entre otros, de Fresnedilla, Navahondilla, Santa María del Tiétar, Santa Cruz o El Hornillo. Se trata de núcleos compactos, con escasos espacios libres, fuertemente renovados y donde se localizan los elementos patrimoniales de valor cultural y las pervivencias de la arquitectura popular tradicional (Arenillas y Burgués, 1990).

Las zonas de ensanche se corresponden con los desarrollos urbanísticos de las últimas décadas, articulados alrededor de los núcleos tradicionales, por lo general siguiendo los antiguos caminos rurales. Se extienden por una superficie del orden de las 193 Has y su mayor o menor superficie está en relación con el dinamismo urbanístico y las diferentes tipologías de promociones inmobiliarias. Los municipios con los ensanches mayores son Sotillo de la Adrada, casi duplica el núcleo tradicional, Candeleda, Arenas de San Pedro, Piedralaves, Casavieja y Lanzahita.

Las urbanizaciones se han convertido en las grandes protagonistas de los crecimientos de las últimas décadas, ocupan una superficie de 715 Has, casi triplican la superficie de los casco antiguos de los pueblos. Este crecimiento se explica por la explosión de la residencia secundaria y los municipios donde las urbanizaciones tienen una mayor presencia son Sotillo de la Adrada, Arenas de San Pedro y La Adrada; en un segundo nivel están Piedralaves, Navahondilla, Candeleda, Casavieja, Santa María del Tiétar, Gavilanes y Lanzahita. Si inicialmente las urbanizaciones se ubicaban fundamentalmente en la cabecera del Valle, en la actualidad ya están presentes en casi todos los municipios.

Históricamente, el Valle del Tiétar ha tenido una importante presencia de hábitat disperso en relación tanto con las actividades agrícolas y ganaderas (casas de labor, majadas, etc.) como con las fabriles (molinos, aserraderos, almazaras, secaderos, etc.) (Troitiño, 1990). Durante las últimas décadas muchas de estas edificaciones se han adecuado para usos turístico/recreativos (casas rurales, viviendas secundarias, bares, restaurantes, etc.) y ello explica que las edificaciones en diseminado ocupen una superficie del orden de 140 has, algo más del 10\% de las superficies edificadas. Los municipios con mayor presencia de diseminado son, a distancia del resto, Candeleda y Arenas de San Pedro, ocupando también superficies por encima de 5 has en Piedralaves, Mombeltrán y Casavieja.

\section{Articulación funcional del Valle del Tiétar y los núcleos rectores del territorio}

La situación geográfica del Valle del Tiétar, una comarca de cruce entre las comunidades autónomas de Castilla y León, Madrid, Castilla- La Mancha y Extremadura, explica articulaciones y dependencias funcionales de signo diverso, en unos casos condicionadas por su ubicación político administrativa y en otros por factores geográficos o económicos. Las relaciones hospitalarias se tienen con Ávila y Talavera y, en menor medida, Salamanca; ocurriendo algo similar en la medicina especializada. En términos territoriales existe una clara diferencia entre el sector 
oriental y occidental de la comarca, así mientras en el occidental las relaciones se distribuyen, de forma pareja, entre Ávila y Talavera de la Reina, en el oriental el protagonismo corresponde a Ávila.

Las relaciones de dependencia con respecto a la enseñanza superior tienen como principales protagonistas a Madrid y Avila, un segundo lugar corresponden a Salamanca y Valladolid (Figura 6). Aquí ya se evidencia que Madrid ejerce un fuerte poder de atracción para los estudiantes de enseñanzas universitarias, tanto por la diversidad de su oferta como por la proximidad geográfica y los vínculos diversos que la comarca siempre ha tenido con la capital de España, hacia donde se ha dirigido y continúa haciéndolo la emigración comarcal.

Figura 6. Valle del Tiétar: relaciones de dependencia, universidad.

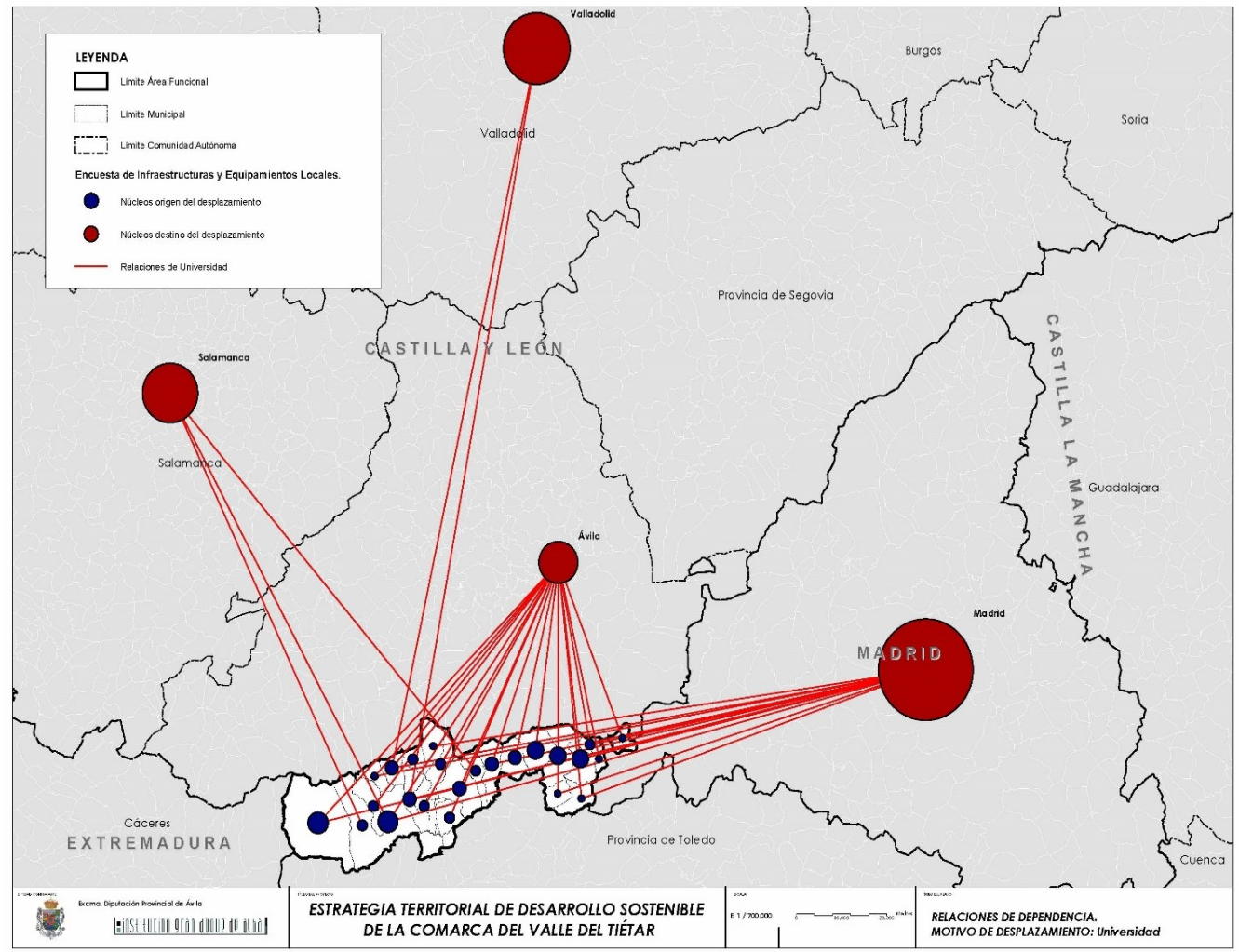

Fuente: Estrategia territorial de desarrollo sostenible de la comarca del Valle del Tiétar. Diputación provincial de Ávila. 2008

Las relaciones y dependencias del comercio especializado se establecen en primer lugar con Talavera de la Reina, Madrid y, en menor medida, Ávila. Los desplazamientos por motivos de ocio se canalizan fundamentalmente hacia Talavera 
de la Reina, por proximidad geográfica, y puntualmente hacia Ávila o Madrid (Figura 7).

La estructura territorial de la comarca, un valle de montaña cuyo horizonte cierran las cumbres del Alto Gredos, las características históricas del modelo de poblamiento y la fragmentación administrativa explican, en alguna medida, que no exista una clara polarización de las relaciones funcionales intra-comarcales. Históricamente se reconocían unas jerarquías y dependencias, las propias de los señoríos, aceptándose la posición dominante de las villas cabecera (Candeleda, Arenas, Mombeltrán, La Adrada e Higuera de las Dueñas). Con las reformas del siglo XIX, el modelo preindustrial se irá desarticulando, algunas villas históricas pierden vínculos administrativos con sus antiguos lugares (Candeleda, Higuera de las Dueñas), otras debilitan su posición (Mombeltrán y La Adrada), Arenas se refuerza y algunos núcleos sin protagonismo histórico, caso de Sotillo, afianzan su papel. En cualquier caso, no hay un núcleo que desempeñe, con claridad, la función de capital o centro comarcal.

Figura 7. Valle del Tiétar: relaciones de dependencia, ocio

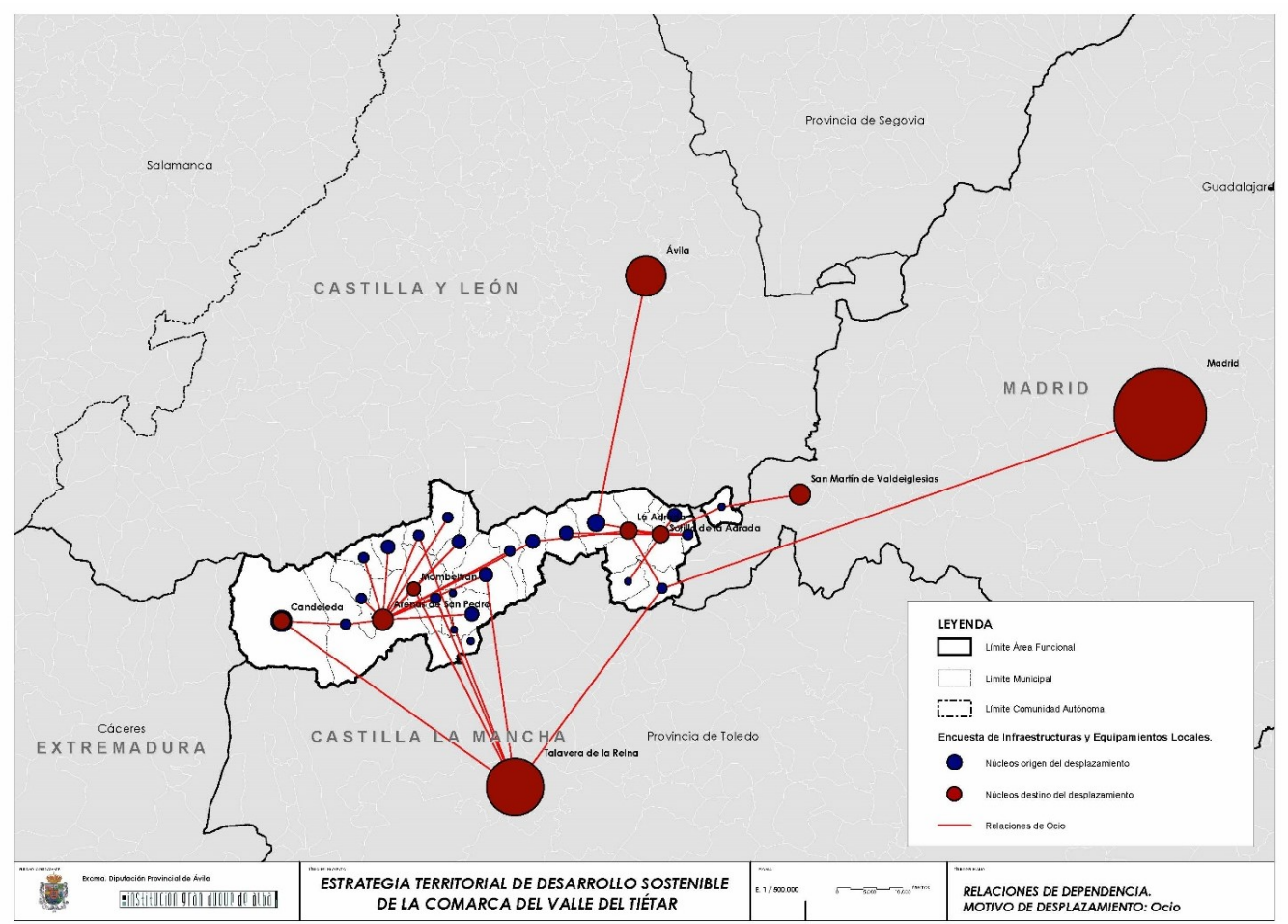

Fuente: Estrategia territorial de desarrollo sostenible de la comarca del Valle del lietar. Diputacion provincial de Ávila. 2008 
A nivel general, en términos de relaciones y dependencias se configuran en la comarca cuatro ámbitos de relaciones y dependencias: uno, el de mayor entidad, vertebrado y articulado claramente por Arenas de San Pedro; un segundo, de menor entidad territorial, en la cabecera del Tiétar, vertebrado por Sotillo de La Adrada, aunque en competencia con La Adrada; un tercero, entre Piedralaves y Lanzahita, a caballo entre los dos polos de actividad más potentes; y finalmente, un cuarto ámbito, en el borde occidental, articulado por Candeleda.

Las relaciones y dependencias a escala comarcal, tal como se aprecia al analizar los equipamientos, están condicionadas por su organización administrativa. En este sentido resultan clarificadores los desplazamientos relacionados con la enseñanza secundaria donde el protagonismo corresponde a Arenas de San Pedro y, ya en menor medida, a Sotillo de La Adrada. En los desplazamientos por motivos de ocio nuevamente sobresale el papel de Arenas de San Pedro, a distancia Sotillo de La Adrada y puntualmente Candeleda y Mombeltrán. En relación al comercio especializado, únicamente Arenas y Sotillo adquieren cierto protagonismo.

La ocupación histórica del territorio dio lugar a un modelo de poblamiento bastante equilibrado con cuatro niveles claramente diferenciados: villas históricas del fondo de valle o laderas bajas; pueblos de tipo medio en las laderas o el interior de los valles serranos; pueblos pequeños; y aldeas dependientes. Este modelo se mantiene en buena medida, pero las jerarquías se han modificado, en sentido positivo para algunos núcleos y, al contrario, en otros. Por ello, considerando las relaciones funcionales de ámbito supramunicipal, se pueden diferenciar tres niveles de núcleos rectores: el nivel superior o comarcal corresponde a Arenas de San Pedro, el subcomarcal, aunque con dinámicas y protagonismos diferentes, a Sotillo de la Adrada y Candeleda y el tercero a La Adrada, Piedralaves y Mombeltrán.

\section{Conclusión}

El Valle del Tiétar se configura como un territorio con entidad geográfica y cultural diferenciada, una comarca geográfica, que no administrativa, identificada por las Directrices de Ordenación del Territorio de Castilla y León como Área Funcional. La estructura actual del poblamiento es reflejo de las transformaciones recientes, vinculadas fundamentalmente con el fuerte crecimiento de la residencia secundaria, la transformación y expansión de los núcleos tradicionales y el abandono o alteración de los asentamientos rurales relacionados con las explotaciones agrarias o ganaderas. Se ha producido una potente difusión territorial de la urbanización y la actividad inmobiliaria ha marcado la dinámica comarcal hasta la crisis de 2008. El patrimonio inmobiliario tiene un potente significado económico y los ingresos municipales tienen una fuerte dependencia del Impuesto de Bienes Inmuebles.

La situación actual del Valle del Tiétar explica articulaciones y dependencias funcionales de signo diverso, en unos casos condicionadas por su ubicación políticoadministrativa en Castilla y León y en otros por su situación geográfica, con diversidad de dependencias externas y un relativo equilibrio intracomarcal. Las 
dependencias funcionales extracomarcales son diversas: Ávila, Talavera, Madrid, Salamanca, Valladolid. Las relaciones funcionales intracomarcales son bastante equilibradas, no existiendo un núcleo que desempeñe el papel de capital o centro comarcal, aun cuando Arenas de San Pedro tenga un importante protagonismo. La estructura bastante equilibrada del poblamiento aconseja apostar por una estrategia de desarrollo territorialmente equilibrada que rentabilicen las potencialidades existentes donde se complementen las distintas zonas de la comarca.

Una entidad geográfica comarcal que por su peculiar situación geográfica, al sur del murallón de Gredos, naturaleza de territorio de cruce e interdependencias funcionales con comarcas vecinas, de Cáceres, Toledo y Madrid, necesita de un reconocimiento político-administrativo diferenciado (Troitiño, 2008) y una reorganización del mapa municipal. Esta realidad debería encontrar encaje en el debate que la Junta de Castilla y León ha abierto en relación con la reorganización del mapa municipal, orientado a lograr una gestión más eficiente del territorio, que el instrumento adecuado sea la comarca o el distrito es una cuestión a dilucidar, en cualquier caso, la entidad comarcal es bien evidente y hay funciones y servicios, medioambientales, urbanísticos, asistenciales, educativos, etc. que deberían afrontarse a esta escala.

\section{Bibliografía y documentación de referencia}

Arenillas, T.; Burgués, J.A. (1990): Asentamientos. En Arenillas et Al.: Gredos. La Sierra y su entorno. MOPU-Instituto de Territorio y Urbanismo. Madrid. Pp.129-149

Arenillas, T. et al. (1990): Gredos. La Sierra y su entorno. MOPU/ Instituto del Territorio y Urbanismo. Madrid.

BOE 1988-785: Ley 27/1987 de 16 de diciembre por la que se establece la organización comarcal de Cataluña y sobre la elección de los consejos comarcales.

BOE 1997-6-7: Ley 8, de 2 de diciembre, de delimitación comarcas de Aragón.

BOE 2013-260. Ley 7/2013, de 27 de septiembre de Ordenación de Servicios y Gobierno del Territorio de la Comunidad de Castilla y León.

Brandis, D; Troitiño, M.Á. (1977). Los paisajes naturales de Ávila. En Martínez de Pisón, E. (coord.) Los paisajes naturales de Segovia, Ávila, Toledo y Cáceres. Estudio Geográfico. Instituto de Estudios de Administración Local. Madrid. Pp. 51-104.

Burgueño, J.; Guerrero, M. (2014). El mapa municipal de España. Una caracterización geográfica. Boletín de la Asociación de Geógrafos Españoles, (64).

Calle, de la M.; García, M. (2006): Turismo en medio rural, conformación y evolución de un sector productivo en plena transformación: el caso del Valle del Tiétar Abulense. Cuadernos de Turismo, 17, pp. 75-102.

Calvi, H; Podii, G. (1988): Pliegos de Ayer. Villa Poyales del Hoyo. Candeleda.

FEMP (2017). Informe Población y Despoblación de España. Comisión de Despoblación. Federación Española de Municipios y Provincias. Madrid.

Instituto Nacional de Estadística. Censo de población. 2016 
Junta de Castilla y León (1985): Estudio y Propuesta de Comarcalización de Castilla y León. Consejería de Presidencia y Administración Territorial. Asistencia Técnica, Consultora EYSER.

Junta de Castilla y León (1996): Directrices de Ordenación del Territorio. Hipótesis de Modelo Territorial. Consejería de Medio Ambiente y Ordenación del Territorio. Valladolid.

Luis, C. (1993): Documentación medieval de los archivos municipales de La Adrada, Candeleda, Higuera de las Dueñas y Sotillo de La Adrada. Colección Fuentes Históricas 14. Institución Gran Duque de Alba- Diputación de Ávila. Ávila.

Martin, M.I.; Hortelano, A.; Plaza, J.I. (2007): Cooperación territorial y gobierno del territorio en Castilla y León. Estudios Geográficos, 263, pp. 547-574.

Martínez, L.C.; Delgado, J.M. (2013): "Población, administración y territorio en Castilla y León: desequilibrios y desafíos del modelo de poblamiento". Ería, 90, pp. 5-30.

Melgosa, J; Troitiño, L. (2015). Boletín Turístico. Centro de Análisis e Innovación Turística de la Provincia de Ávila.

Ministerio de Agricultura, Alimentación y Medio Ambiente (2014): Caracterización de las comarcas agrarias de España. Tomo 8. Provincia de Ávila. Madrid.

Molino, S. Del (2016). La España vacía. Viaje por un país que nunca fue. Turner. Madrid.

Santos, L.; Peiret, A. (2001): Articulación Regional y Comarcas en Castilla y león: Las Directrices de Ordenación del Territorio. Boletín de la Asociación de Geógrafos Españoles 32, pp. 177-190.

Solís Trapero, E. (2011): Del área metropolitana hacia la región urbana policéntrica madrileña: cambio de escala, estructura y articulación territorial. Universidad Complutense de Madrid. eprint

Tejero Robledo, Ed. (1990): Arenas de San Pedro y el Valle del Tiétar. Fundación Marcelo Gómez Matías. Arenas de San Pedro.

Troitiño, M.A. (1990): La Ocupación del Territorio de la Sierra de Gredos. Proceso Histórico. En Arenillas Parra, T. et Al. Gredos. La Sierra y su entorno. MOPU. Instituto del Territorio y Urbanismo. Madrid. Pp.75-98.

Troitiño, M.A. (1997): Problemas territoriales y medioambientales en el Valle del Tiétar abulense. Trasierra, Boletín de la Sociedad de Estudios del Valle del Tiétar, 2, pp. 59-80.

Troitiño, M.A. (1999): Evolución histórica y cambios en la organización del territorio del Valle del Tiétar Abulense. Diputación Provincial de Ávila. Institución Gran Duque de Alba. Ávila.

Troitiño, M.A. (Dir. 2008): Estrategia de Desarrollo Territorial Sostenible del Valle del Tiétar. Diputación Provincial de Ávila. Institución Gran Duque de Alba (inédito).

Troitiño, M.A.; Troitiño, L. (2016): Estrategia de Desarrollo Territorial Sostenible en el Valle del Tiétar Abulense. En VIII Congreso Internacional de Ordenación del Territorio/ Derecho Urbanístico. FUNDICOT. Madrid. Pp. 380-240. 